\title{
Age and diabetes mellitus associated with worse outcomes after percutaneous coronary intervention in a multi-ethnic Asian dialysis patient population
}

\author{
Jiang Ming $\underline{\mathrm{Fam}}^{1}$, MBBS, PhD, Chun Yuan $\underline{K h o O}^{1}$, MBBS, MRCP, Yee How Lau ${ }^{1}$, BSc, Weng Kit $\underline{\mathrm{Lye}}^{2}$, MSc, \\ Xinzhe James $\underline{\mathrm{Cai}}^{1}$, MBBS, MRCP, Lina Hui Lin $\underline{C h o o n g}^{3}$, MBBS, John Carson Allen ${ }^{2}$, PhD, Khung Keong $\underline{\text { Yeo }}^{1}$, MBBS
}

\begin{abstract}
INTRODUCTION There is limited literature on clinical outcomes following percutaneous coronary intervention (PCI) in Asian dialysis patients. We evaluated the angiographic characteristics and clinical outcomes of dialysis patients treated with $\mathrm{PCl}$ in an Asian society.

METHODS A retrospective analysis was performed of 274 dialysis patients who underwent $\mathrm{PCl}$ in a tertiary care institution from January 2007 to December 2012. Data on clinical and angiographic characteristics was collected. The primary endpoint was major adverse cardiac events (MACE), defined as a composite of cardiac death, acute myocardial infarction (AMI) and stroke at two years.

RESULTS 274 patients (65.0\% male, median age 62.0 years) with 336 lesions (81.8\% Type B2) were treated. 431 stents (35.0\% drug-eluting stents) with a mean diameter of $2.96 \mathrm{~mm}$ and mean length of $21.30 \mathrm{~mm}$ were implanted. The MACE rate was $55.8 \%(n=153)$ at two years, from death $(36.5 \%)$ and AMI $(35.0 \%)$. In multivariable analysis, age and diabetes mellitus were significant predictors of both mortality (odds ratio [OR] 1.09, 95\% confidence interval [Cl] 1.05-1.12, $\mathrm{p}<0.001$; OR 2.65, 95\% Cl 1.46-4.82, $\mathrm{p}=0.001$, respectively) and MACE (OR 1.06, 95\% Cl 1.03-1.08, p < 0.001; OR $1.84,95 \% \mathrm{Cl} 1.07-3.15, p=0.027$, respectively). Left ventricular ejection fraction (LVEF) (OR 0.97, 95\% CI 0.95-0.99, $\mathrm{p}=0.006$ ) was a significant predictor of mortality but not MACE.

CONCLUSION Asian dialysis patients who underwent $\mathrm{PCl}$ had a two-year MACE rate of $55.8 \%$ due to death and AMI. Age, LVEF and diabetes mellitus were significant predictors of mortality at two years.
\end{abstract}

Keywords: coronary artery disease, percutaneous coronary intervention, renal dialysis

\section{INTRODUCTION}

Patients with ESRD (end-stage renal disease) on dialysis have an increased risk of cardiovascular disease (CVD), ${ }^{(1,2)}$ and tend to develop diffuse and complex lesions in the coronaries. In addition, dialysis patients tend to have more calcified lesions, ${ }^{(3)}$ which may be associated with an increased risk of adverse clinical outcomes. ${ }^{(4)} \mathrm{CVD}$ is also one of the main causes of death in ESRD patients, with a reported annual mortality rate of $18 \%-20 \% .{ }^{(5-10}$ Local data shows that approximately one-third of deaths in dialysis patients are due to cardiac causes. ${ }^{(11)}$

Among CVD patients, the presence of chronic renal disease is associated with worse cardiovascular outcomes. ${ }^{(12)}$ Reasons postulated for this causal relationship include the presence of oxidative stress and inflammation, which are linked to the pathogenesis of plaque formation and rupture, mineralocorticoid excess, ${ }^{(13)}$ platelet dysfunction, and disruption in calcium and bone metabolism, ${ }^{(14)}$ possibly contributing to monocyte activation and endothelial dysfunction of the coronaries.

Percutaneous coronary intervention $(\mathrm{PCl})$ has been the mainstay of treatment options in patients with ischaemic heart disease. However, $\mathrm{PCl}$ in patients with ESRD has been shown to be associated with high periprocedural mortality and poor clinical outcome, with increased rates of in-hospital and long-term mortality, myocardial infarction (MI), bleeding complications, and clinical and angiographic restenosis when compared to patients without ESRD. ${ }^{(15-18)}$ As there is limited data on the extent of this relationship in Asian patients, the present study aimed to evaluate the clinical outcomes following PCI in ESRD patients on dialysis in an Asian geopolitical setting.

\section{METHODS}

We conducted a retrospective analysis of patients who (a) underwent PCl from January 2007 to December 2012 in our centre; and (b) had been on dialysis for three months or longer. Baseline clinical and angiographic characteristics were collected from our institutional database.

Dedicated personnel from an institution performed all data management and analysis. Prespecified demographic data, clinical data and diagnosis codes were obtained from hospital data. The primary endpoint was major adverse cardiac events (MACE), defined as the composite endpoint of cardiac death, MI and stroke at two years, and was hierarchical in nature. The events of death, $\mathrm{Ml}$ and stroke were individually tracked from national registries whose disease codes were based on hospital diagnosis codes and national registry data. Deaths were considered cardiac unless a non-cardiac cause was definitely identified. Angiographic success rate was defined as improvement in thrombolysis in myocardial infarction (TIMI) flow and improvement in stenosis

${ }^{1}$ Department of Cardiology, National Heart Centre Singapore, ${ }^{2}$ Duke-NUS Medical School, ${ }^{3}$ Department of Nephrology, Singapore General Hospital, Singapore Correspondence: Dr Jiang Ming Fam, Consultant, Department of Cardiology, National Heart Centre Singapore, 5 Hospital Drive, Singapore 169609. fam.jiang.ming@singhealth.com.sg 
of the lesion to less than $30 \%$ (based on visual estimation). Procedural success rate was defined as angiographic success rate without any periprocedural or intrahospital complications of mortality, acute MI or stroke. Target vessel revascularisation was defined as any repeat percutaneous intervention of any segment of the target vessel.

Continuous variables were expressed as mean \pm standard deviation (SD) or median (interquartile range [IQR]) as appropriate, while categorical variables were expressed as number and percentage. For cumulative event rates, Kaplan-Meier estimates were described and non-hierarchical counts were used. Multivariable logistic regression analysis was performed to model independent predictors of clinical outcomes. Variables included in the multivariable model were age, diabetes mellitus (DM), saphenous vein graft intervention, hypertension, smoking, acute coronary syndrome, hyperlipidaemia and left ventricle ejection fraction (LVEF). Variables with missing values of more than $20 \%$ were imputed using the mean value. Two sets of data (i.e. with and without imputation) were analysed and the results of the former were reported if similar results were found in the latter. Statistical analysis was performed using SAS 9.4 (SAS Institute Inc, Cary, NC, USA). A p-value $<0.05$ was considered significant.

\section{RESULTS}

A total of 18,239 patients who underwent elective $\mathrm{PCl}$ between January 2007 and December 2012 were identified. 274 (1.5\%) patients were on dialysis for a period longer than three months at the time of $\mathrm{PCl}$. Baseline clinical and demographic results are shown in Table I. $65.0 \%$ of the patients were male and the median age was 62.0 (IQR 54.0-69.0) years. DM and hypertension were present in $63.9 \%$ and $94.5 \%$ of the dialysis patients, respectively. $9.5 \%(n=26)$ and $27.4 \%(n=75)$ of all the patients were admitted for ST-elevation $\mathrm{Ml}$ and acute coronary syndrome, respectively. The majority $(86.5 \%, \mathrm{n}=237)$ of the patients underwent haemodialysis and $38.7 \%(n=106)$ had been on dialysis for 2-5 years.

Angiographic results are shown in Table II. A total of 336 lesions were treated. The most common vessel treated was the left anterior descending artery $(43.8 \%, \mathrm{n}=147)$. The majority $(81.8 \%, n=275)$ of the lesions were complex lesions (i.e. American Heart Association type B2) and moderately to heavily calcified $(65.5 \%, \mathrm{n}=220) .431$ metallic stents, $35.0 \%$ of which were drug-eluting stents (DES), were implanted in 308 lesions (Table III). The remaining lesions were treated with balloon angioplasty $(8.3 \%, \mathrm{n}=28)$. Mean stent diameter and length were $2.96 \pm 0.48 \mathrm{~mm}$ and $21.30 \pm 7.47 \mathrm{~mm}$, respectively. Intravascular ultrasonography was used in $4.7 \%$ of the procedures. Lesion preparation was required in the majority of the procedures. Predilation was performed in $89.5 \%$ of them, while debulking using scoring/cutting balloons and rotational atherectomy were performed in $4.0 \%(n=11)$ and $5.8 \%(n=16)$ of the procedures, respectively. Post-stenting balloon dilation was also performed in $61.7 \%$ of the procedures.

Clinical outcomes are shown in Table IV. The procedural angiographic success rate was $96.4 \%(\mathrm{n}=264)$, and the
Table I. Clinical and demographic characteristics of the patients ( $n=274)$.

\begin{tabular}{|c|c|}
\hline Characteristic & No. (\%) \\
\hline 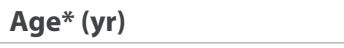 & $62.0(54.0-69.0)$ \\
\hline Male gender & $178(65.0)$ \\
\hline \multicolumn{2}{|l|}{ Ethnicity } \\
\hline Chinese & $196(71.5)$ \\
\hline Malay & $54(19.7)$ \\
\hline Indian & $18(6.6)$ \\
\hline Others & $6(2.2)$ \\
\hline Prior MI & $88(32.1)$ \\
\hline STEMI & $26(9.5)$ \\
\hline ACS & $75(27.4)$ \\
\hline Prior revascularisation & $89(32.5)$ \\
\hline Prior PTCA & $51(18.6)$ \\
\hline Prior CABG & $46(16.8)$ \\
\hline Diabetes mellitus & $175(63.9)$ \\
\hline Hypertension & $259(94.5)$ \\
\hline Hyperlipidaemia & $218(79.6)$ \\
\hline Smoking $^{\dagger}$ & $33(12.0)$ \\
\hline LVEF & $45.0(35.0-57.0)$ \\
\hline Haemodialysis & $237(86.5)$ \\
\hline \multicolumn{2}{|l|}{ Duration of dialysis } \\
\hline$>3 \mathrm{mth}$ to $<2 \mathrm{yr}$ & $71(25.9)$ \\
\hline$\geq 2 \mathrm{yr}$ to $5 \mathrm{yr}$ & $106(38.7)$ \\
\hline $6-10 \mathrm{yr}$ & $62(22.6)$ \\
\hline$>10 \mathrm{yr}$ & $35(12.8)$ \\
\hline \multicolumn{2}{|l|}{ Concomitant kidney disease } \\
\hline Glomerulonephritis & $25(9.1)$ \\
\hline Pyelonephritis & $1(0.4)$ \\
\hline Polycystic kidney disease & $9(3.3)$ \\
\hline Others & $6(2.2)$ \\
\hline
\end{tabular}

*Data is presented as median (interquartile range). +Current smoker/recent smoker (within $1 \mathrm{yr}$ ) prior to hospital admission. ACS: acute coronary syndrome; CABG: coronary artery bypass surgery; ESRF: end-stage renal failure; LVEF: left ventricular ejection fraction; MI: myocardial infarction; PTCA: percutaneous coronary angioplasty; STEMI: ST-elevation myocardial infarction

procedural success rate was $91.6 \%(\mathrm{n}=251)$. There were $12(4.4 \%)$ cases of in-hospital mortality. The hierarchical MACE rate was $55.8 \%(\mathrm{n}=153)$ at two years, contributed mainly by death (36.5\%, $\mathrm{n}=100$; Appendix, Supplementary Fig. 1) and acute $\mathrm{MI}(35.0 \%, \mathrm{n}=96)$. Target vessel revascularisation rate at one and two years was $9.9 \%(n=27)$ and $13.1 \%(n=36)$, respectively. $2.2 \%(n=6)$ of patients underwent coronary artery bypass surgery within two years after the index $\mathrm{PCl}$.

Predictors of clinical outcomes are shown in the Appendix. In multivariable analysis, age (odds ratio [OR] 1.09, 95\% confidence interval [CI] 1.05-1.12; $p<0.001)$, LVEF (OR 0.97, 95\% Cl $0.95-0.99 ; \mathrm{p}=0.006)$ and the presence of DM (OR 2.65, 95\% $\mathrm{Cl} 1.46-4.82 ; \mathrm{p}=0.001$ ) were significant predictors of mortality at two years. Of note, ethnicity was not a significant predictor of clinical outcomes in this study. Survival curves for two-year mortality in the presence of DM and LVEF are shown in Fig. 1. The two-year survival rate was significantly lower in patients with 
Table II. Angiographic characteristics of the lesions $(n=336)$.

\begin{tabular}{|c|c|}
\hline Characteristic & No. (\%) \\
\hline \multicolumn{2}{|l|}{ Vessel location } \\
\hline Left main & $12(3.6)$ \\
\hline Left anterior descending & $147(43.8)$ \\
\hline Left circumflex & $55(16.4)$ \\
\hline Right coronary & $106(31.5)$ \\
\hline Saphenous vein graft & $14(4.2)$ \\
\hline Arterial graft & $2(0.6)$ \\
\hline Ostial & $3(0.9)$ \\
\hline Bifurcation & $164(66.1)$ \\
\hline Chronic total occlusion & $19(5.7)$ \\
\hline \multicolumn{2}{|l|}{ Calcification } \\
\hline Mild & $116(34.5)$ \\
\hline Moderate & $168(50.0)$ \\
\hline Severe & $52(15.5)$ \\
\hline \multicolumn{2}{|l|}{ AHA classification } \\
\hline Type A & $3(0.9)$ \\
\hline Type B1 & $25(7.4)$ \\
\hline Type B2 & $275(81.8)$ \\
\hline Type C & $33(9.8)$ \\
\hline De novo lesion & $329(97.9)$ \\
\hline In-stent restenosis & $7(2.1)$ \\
\hline No. of lesions that underwent balloon angioplasty & $28(8.3)$ \\
\hline No. of lesions stented & $308(91.7)$ \\
\hline \multicolumn{2}{|l|}{ TIMI grade } \\
\hline \multicolumn{2}{|l|}{ Preprocedure } \\
\hline 0 & $28(8.3)$ \\
\hline 1 & $10(3.0)$ \\
\hline 2 & $15(4.5)$ \\
\hline 3 & $283(84.2)$ \\
\hline \multicolumn{2}{|l|}{ Postprocedure } \\
\hline 0 & $8(2.4)$ \\
\hline 1 & $2(0.6)$ \\
\hline 2 & $2(0.6)$ \\
\hline 3 & $324(96.4)$ \\
\hline
\end{tabular}

*Data presented as median (interquartile range) or mean \pm standard deviation. tBifurcation is defined as side branch $\geq 2 \mathrm{~mm}$. AHA: American Heart Association; TIMI: thrombolysis in myocardial infarction

DM compared to those without DM (two-year survival rate: $57 \%$ vs. 76\%; $p=0.0025)$. In multivariable analysis, age (OR 1.06, 95\% Cl 1.03-1.08; $p<0.001)$ and the presence of DM (OR 1.84, 95\% Cl 1.07-3.15; $p=0.027$ ) were significant predictors of MACE at two years. There was a trend towards lower two-year MACE-free survival in DM compared to non-DM patients (39\% vs. 54\%; $\mathrm{p}=$ $0.0670)$, although this relationship was not statistically significant (Appendix, Supplementary Fig. 2).

\section{DISCUSSION}

Although advances in interventional techniques have led to improvement in clinical outcomes in patients who undergo $\mathrm{PCl}$, cardiovascular disease remains the leading cause of death in dialysis patients, and the presence of chronic kidney disease is
Table III. Procedural details for the 274 patients, based on 431 implanted stents.

\begin{tabular}{|c|c|}
\hline Parameter & No. (\%) \\
\hline Mean stent diameter* (mm) & $2.96 \pm 0.48$ \\
\hline Mean stent length* (mm) & $21.30 \pm 7.47$ \\
\hline Total stent length* (mm) & $29.80 \pm 17.90$ \\
\hline \multicolumn{2}{|l|}{ Treatment of lesions $(n=431)$} \\
\hline Bare metal stents & $280(65.0)$ \\
\hline Drug-eluting stents & $151(35.0)$ \\
\hline No. of stents per vessel* & $1.4 \pm 0.7$ \\
\hline \multicolumn{2}{|l|}{ Multiple vessels treated $(n=274)$} \\
\hline Triple vessel & $4(1.5)$ \\
\hline Left main & $12(4.4)$ \\
\hline IVUS $(n=274)$ & $13(4.7)$ \\
\hline OCT $(n=274)$ & $0(0)$ \\
\hline Scoring/cutting balloon $(n=274)$ & $11(4.0)$ \\
\hline Rotational atherectomy $(n=274)$ & $16(5.8)$ \\
\hline Predilation performed $(n=248)$ & $222(89.5)$ \\
\hline Postdilation performed $(n=248)$ & $153(61.7)$ \\
\hline
\end{tabular}

Percentages are calculated based on number of stents or patients, as appropriate. *Data presented as mean \pm standard deviation. IVUS: intravascular ultrasound; OCT: optical coherence tomography

Table IV. Clinical outcomes of the patients $(n=274)$.

\begin{tabular}{|ll|}
\hline Outcome & No. (\%) \\
\hline Procedural outcome & $264(96.4)$ \\
\hline Angiographic success & $251(91.6)$ \\
\hline Clinical success & \\
\hline 1-year outcome & $62(22.6)$ \\
\hline Death & $52(19.0)$ \\
\hline AMl & $8(2.9)$ \\
\hline Stroke & $88(32.1)$ \\
\hline MACE* & \\
\hline 2-year outcomes & $100(36.5)$ \\
\hline Death & $96(35.0)$ \\
\hline AMl & $11(4.0)$ \\
\hline Stroke & $153(55.8)$ \\
\hline MACE* & \\
\hline Target vessel revascularisation & $27(9.9)$ \\
\hline At 1 yr & $36(13.1)$ \\
\hline At 2 yr & \\
\hline Coronary artery bypass surgery & $5(1.8)$ \\
\hline At 1 yr & $6(2.2)$ \\
\hline At 2 yr
\end{tabular}

*Hierarchical. AMI: acute myocardial infarction; MACE: major adverse cardiovascular events

an independent risk factor for MACE in high-risk populations. ${ }^{(19,20)}$ Unfortunately, most major randomised clinical trials that form the basis for evidence-based use of revascularisation procedures exclude patients who are on renal dialysis. ${ }^{(21)}$

Initial reports appeared in 2000 addressing the impact of chronic renal failure on outcome after $\mathrm{PCl}$, based on a small case-control study with 66 patients $^{(22)}$ and a large cross-sectional study of 362 patients. ${ }^{(23)}$ Both trials assessed long-term survival 

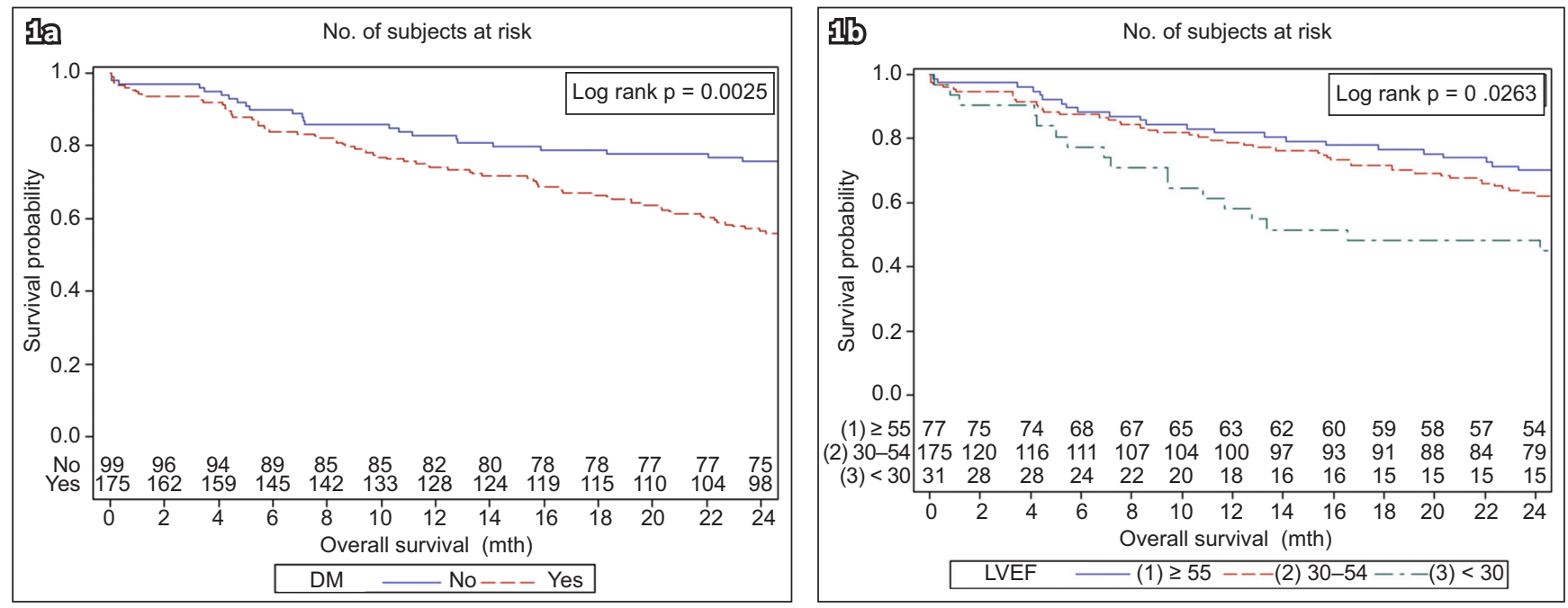

Fig. 1 (a) Two-year Kaplan-Meier curve for hierarchical major adverse cardiovascular events stratified by the presence of diabetes mellitus (DM) shows that the two-year survival rate was significantly lower in DM compared to non-DM patients (57\% vs. 76\%; $p=0.0025)$. (b) Kaplan-Meier curve for twoyear survival stratified by left ventricular ejection fraction (LVEF) shows that the two-year survival rate was significantly lower in patients with reduced LVEF $(48 \%$ for LVEF < 30\%, $62 \%$ for LVEF 30\%-54\%, 70\% for LVEF $\geq 55 \%$; $p=0.0263$ ).

in patients with chronic renal disease and without a history of haemodialysis. They found markedly higher in-hospital and long-term mortality in these patients, with an overall survival of only $60 \%$ after 3-4 years. However, limited data was available on renal dialysis patients, particularly in the Asian population, which may have a higher prevalence of DM and renal disease. ${ }^{(24}$

The two-year mortality rate of $36.5 \%$ in this study was comparable to those of earlier studies done in other populations. ${ }^{(5-10)}$ In the study by Hertzog et $\mathrm{al}^{(17)}$ on dialysis patients in the United States, two-year survival was $48.4 \% \pm$ $2.0 \%$ in the stent group and $48.2 \% \pm 1.5 \%$ after percutaneous transluminal coronary angioplasty (PTCA). In our study, the risks of all-cause mortality and MACE at two years were considerably higher in older patients and in patients with DM. Age was also shown to be a significant risk factor affecting prognosis in an earlier study by Rubenstein et al, ${ }^{(23)}$ in which 362 renal failure patients were compared with 2,972 patients with normal renal function who underwent PCI between 1994 and 1997. Patients with renal failure were older and had more associated comorbidities, reduced procedural success $(89.5 \%$ vs. $92.9 \% ; p<0.007$ ) and greater in-hospital combined major event rates (i.e. death, Q-wave $\mathrm{Ml}$ and emergent coronary artery bypass surgery) $(10.8 \%$ vs. $1.8 \%$; $p<0.0001)$. Cox regression analysis identified age $>74$ years (relative risk [RR] 1.8, 95\% Cl 1.3-2.5; $\mathrm{p}<0.001$ ), PTCA strategy (RR 1.7, 95\% Cl 1.1-2.5; $\mathrm{p}<0.01$ ) and female gender (RR 1.4, 95\% Cl 1.0-2.0; $\mathrm{p}<0.07$ ) as independent predictors of MACE at long-term follow-up in the renal group.

In our study, DM was a significant independent predictor of clinical outcomes following $\mathrm{PCl}$ in dialysis patients. The presence of DM was associated with a nearly twofold increase in mortality (OR 2.65, 95\% Cl 1.46-4.82; $\mathrm{p}=0.001)$ and MACE (OR $1.84,95 \%$ Cl 1.07-3.15; $p=0.027$ ) (Appendix, Supplementary Tables I \& II). This was consistent with previous studies, ${ }^{(19)}$ which suggested that DM was associated with higher ischaemic burden in ESRD patients.
The poor prognosis for post- $\mathrm{PCl}$ Asian dialysis patients may be multifactorial. Possible reasons include greater complexity of the lesions treated (greater calcification and medial thickness of the coronary plaque), increased risk of in-stent restenosis after $\mathrm{PCl}$, poor control of underlying cardiovascular risk factors, greater vascular inflammation, and increased thrombogenicity from endothelial dysfunction and atherosclerosis secondary to the accumulation of uremic toxins. ${ }^{(25,26)}$ In addition, patients on dialysis are typically also older and have more comorbidities. ${ }^{(16,27)}$ The higher event rates seen in our study may partially be attributed to the relatively low usage of DES, which were shown to have better clinical outcomes than bare metal stents (BMS). ${ }^{(28)}$ In one study ${ }^{(29)}$ that compared the results of $\mathrm{PCl}$ using BMS with those of DES in 350 chronic renal failure patients (defined as creatinine clearance $<60 \mathrm{~mL} /$ minute), cardiovascular death and MACE occurred less frequently in DES groups. The target lesion revascularisation (TLR) rate was not significantly different in the chronic renal failure groups (BMS 9.8\% vs. DES 7.1\%; $p=0.44$ ). No excess of stent thrombosis was observed in the DES groups, and the use of DES was independently associated with absence of MACE and TLR. In our study, the relatively low rate of unplanned target vessel revascularisation on follow-up (Table IV) suggested that the patients were subsequently treated medically, which may partially contribute to the high mortality rate. Commonly, patients who undergo medical therapy are likely to be those who have advanced age, multiple comorbidities and high bleeding risk, and are therefore considered high risk for further invasive procedures.

The results of our study reinforce our understanding of the high MACE rate following $\mathrm{PCl}$ in Asian chronic dialysis patients. More studies are needed to evaluate the impact of different revascularisation options in dialysis patients, the impact of bleeding complications on $\mathrm{PCl}$ outcomes and the effect of new pharmacological therapies on clinical outcomes.

The limitations of our study include the inherent limitations of a retrospective study and its relatively small sample size of a single centre. Further research is needed to assess whether the 
use of additional clinical characteristics or biomarkers might contribute to more effective risk prediction and better care for dialysis patients undergoing $\mathrm{PCl}$.

In conclusion, Asian dialysis patients who underwent $\mathrm{PCl}$ have a two-year MACE rate of 55.8\%, mainly due to death and acute MI. Age, impaired LVEF and DM were significant predictors of mortality at two years. Dialysis patients represent a group of high-risk patients who are frequently excluded from clinical trials involving treatment with coronary artery stents. This study shows that dialysis patients in this multiracial Asian geopolitical setting have a relatively high incidence of adverse medical outcomes up to two years post $\mathrm{PCl}$ and should be counselled appropriately. Further studies are needed to further evaluate the impact of revascularisation on long-term clinical outcomes.

\section{SUPPLEMENTARY MATERIAL}

The Appendix is available online at https://doi.org/10.11622/ smedj.2020025.

\section{REFERENCES}

1. Washam JB, Herzog CA, Beitelshees AL, et al. Pharmacotherapy in chronic kidney disease patients presenting with acute coronary syndrome: a scientific statement from the American Heart Association. Circulation 2015; 131:1123-49.

2. Go AS, Chertow GM, Fan D, McCulloch CE, Hsu CY. Chronic kidney disease and the risks of death, cardiovascular events, and hospitalization. N Engl J Med 2004; 351:1296-305.

3. Ix JH, Shlipak MG, Liu HH, Schiller NB, Whooley MA. Association between renal insufficiency and inducible ischemia in patients with coronary artery disease: the heart and soul study. J Am Soc Nephrol 2003; 14:3233-8.

4. Onuma $Y$, Tanimoto S, Ruygrok $P$, et al. Efficacy of everolimus eluting stent implantation in patients with calcified coronary culprit lesions: two-year angiographic and three-year clinical results from the SPIRIT II study. Catheter Cardiovasc Interv 2010; 76:634-42.

5. Lindner A, Charra B, Sherrad DJ, Scribner BH. Accelerated atherosclerosis in prolonged maintenance hemodialysis. N Engl J Med 1974; 290:697-701.

6. Hellerstedt WL, Johnson WJ, Ascher N, et al. Survival rates of 2,728 patients with end-stage renal disease. Mayo Clin Proc 1984; 59:776-83.

7. Gokal R, Jakubowski C, King J, et al. Outcome in patients on continuous ambulatory peritoneal dialysis and haemodialysis: 4-year analysis and prospective multicentre study. Lancet 1987; 2:1105-9.

8. United States Renal Data System. 1997 annual data report. Bethesda, MD: National Institute of Diabetes and Digestive and Kidney Diseases, 1997: 91-101.

9. Kasiske BL, Guijarro C, Massy ZA, Wiederkehr MR, Ma JZ. Cardiovascular disease after renal transplantation. J Am Soc Nephrol 1996; 77:158-65.

10. Rinehart AL, Herzog CA, Collins AJ, et al. A comparison of coronary angioplasty and coronary artery bypass grafting outcomes in chronic dialysis patients. Am J Kidney Dis 1995; 25:281-90.
11. National Registry of Diseases Office, Health Promotion Board, Singapore. Singapore Renal Registry Annual Report 2015. Available at: https://www. nrdo.gov.sg/docs/librariesprovider3/default-document-library/singapore-renalregistry-annual-report-2015.pdf?sfvrsn=0. Accessed February 8, 2017.

12. Joki N, Hase H, Nakamura R, Yamaguchi T. Onset of coronary artery disease prior to initiation of haemodialysis in patients with end-stage renal disease. Nephrol Dial Transplant 1997; 12:718-23.

13. deFilippi C, Wasserman S, Rosanio S, et al. Cardiac troponin T and C-reactive protein for predicting prognosis, coronary atherosclerosis, and cardiomyopathy in patients undergoing long-term hemodialysis. JAMA 2003; 290:353-9.

14. Giovannucci E, Liu Y, Hollis BW, Rimm EB. 25-hydroxyvitamin D and risk of myocardial infarction in men: a prospective study. Arch Intern Med 2008; 168:1174-80.

15. Agirbasli M, Weintraub WS, Chang GL, et al. Outcome of coronary revascularization in patients on renal dialysis. Am J Cardiol 2000; 86:395-9.

16. Gruberg L, Dangas G, Mehran R, et al. Clinical outcome following percutaneous coronary interventions in patients with chronic renal failure. Catheter Cardiovasc Interv 2002; 55:66-72.

17. Herzog CA, Ma JZ, Collins AJ. Comparative survival of dialysis patients in the United States after coronary angioplasty, coronary artery stenting, and coronary artery bypass surgery and impact of diabetes. Circulation 2002; 106:2207-11.

18. Shroff GR, Solid CA, Herzog CA. Long-term survival and repeat coronary revascularization in dialysis patients after surgical and percutaneous coronary revascularization with drug-eluting and bare metal stents in the United States. Circulation 2013; 127:1861-9.

19. Sarnak MJ, Levey AS, Schoolwerth AC, et al. Kidney disease as a risk factor for development of cardiovascular disease: a statement from the American Heart Association Councils on Kidney in Cardiovascular Disease, High Blood Pressure Research, Clinical Cardiology, and Epidemiology and Prevention. Circulation 2003; 108:2154-69.

20. Popma JJ, Kuntz RE, Baim DS. A decade of improvement in the clinical outcomes of percutaneous coronary intervention for multivessel coronary artery disease. Circulation 2002; 106:1592-4.

21. Ashrith G, Elayda MA, Wilson JM. Revascularization options in patients with chronic kidney disease. Tex Heart Inst J 2010; 37:9-18.

22. Reinecke H, Matzkies F, Regetmeier A et al. Stable renal failure, and acute and long-term outcome after PTCA. Eur Heart J 2000; 21 [Suppl]: 168.

23. Rubenstein MH, Harrell LC, Sheynberg BV, et al. Are patients with renal failure good candidates for percutaneous coronary revascularization in the new device era? Circulation 2000; 102:2966-72.

24. Tadros GM, Herzog CA. Percutaneous coronary intervention in chronic kidney disease patients. J Nephrol 2004; 17:364-8.

25. Bolton $\mathrm{CH}$, Downs LG, Victory JG, et al. Endothelial dysfunction in chronic renal failure: roles of lipoprotein oxidation and pro-inflammatory cytokines. Nephrol Dial Transplant 2001; 16:1189-97.

26. Pecoits-Filho R, Heimbürger $O$, Bárány $P$, et al. Associations between circulating inflammatory markers and residual renal function in CRF patients. Am J Kidney Dis 2003; 41:1212-8.

27. Cardone KE, Bacchus S, Assimon MM, Pai AB, Manley HJ. Medication-related problems in CKD. Adv Chronic Kidney Dis 2010; 17:404-12.

28. Stettler C, Wandel S, Allemann S, et al. Outcomes associated with drug-eluting and bare-metal stents: a collaborative network meta-analysis. Lancet 2007; 370:937-48.

29. Barthelemy O, Helft G, Silvain J, et al. One-year clinical outcomes in patients with chronic renal failure treated by percutaneous coronary intervention with drug-eluting stent. Arch Cardiovasc Dis 2011; 104:604-10. 
APPENDIX

Supplementary Table I. Predictors of mortality at two years $(\mathbf{n}=\mathbf{2 7 4})$.

\begin{tabular}{|l|l|l|l|l|}
\hline Predictor & OR (95\% CI) & p-value & Adjusted OR (95\% CI) & p-value \\
\hline Age & $1.08(1.05-1.11)$ & $<0.001$ & $1.09(1.05-1.12)$ & $<0.001$ \\
\hline LVEF$^{*}$ & $0.98(0.96-0.99)$ & 0.009 & $0.97(0.95-0.99)$ & 0.006 \\
\hline Diabetes mellitus & $2.40(1.39-4.15)$ & 0.002 & $2.65(1.46-4.82)$ & 0.761 \\
\hline Hypertension & $0.64(0.23-1.82)$ & 0.403 & $0.83(0.26-2.72)$ & 0.552 \\
\hline Saphenous vein graft & $1.80(0.61-5.28)$ & 0.287 & $1.42(0.45-4.50)$ & \\
\hline
\end{tabular}

*Missing data in LVEF was imputed by using the mean LVEF of 237 (45.5\%) patients. Cl: confidence interval; LVEF: left ventricular ejection fraction; OR: odds ratio

Supplementary Table II. Predictors of major adverse cardiovascular events at two years.

\begin{tabular}{|l|l|l|l|l|}
\hline Predictor & OR (95\% CI) & p-value & Adjusted OR (95\% CI) & p-value \\
\hline Age & $1.05(1.03-1.08)$ & $<0.001$ & $1.06(1.03-1.08)$ & $<0.001$ \\
\hline Diabetes mellitus & $1.81(1.10-2.98)$ & 0.019 & $1.84(1.07-3.15)$ & 0.027 \\
\hline LVEF* & $0.98(0.96-1.00)$ & 0.103 & $0.99(0.97-1.01)$ & 0.190 \\
\hline Hypertension & $0.44(0.14-1.42)$ & 0.171 & $0.42(0.11-1.56)$ & 0.194 \\
\hline ACS & $0.65(0.38-1.10)$ & 0.110 & $0.61(0.34-1.10)$ & 0.098 \\
\hline Hyperlipidaemia & $0.64(0.35-1.18)$ & 0.155 & $0.67(0.34-1.29)$ & 0.230 \\
\hline Smoking & $0.54(0.26-1.13)$ & 0.102 & $0.65(0.29-1.45)$ & 0.291 \\
\hline Saphenous vein graft & $1.06(0.36-3.13)$ & 0.920 & $0.96(0.30-3.04)$ & 0.937 \\
\hline
\end{tabular}

*Missing data in LVEF was imputed by using the mean LVEF of 237 (45.5\%) patients. ACS: acute coronary syndrome; Cl: confidence interval; LVEF: left ventricular ejection fraction; OR: odds ratio

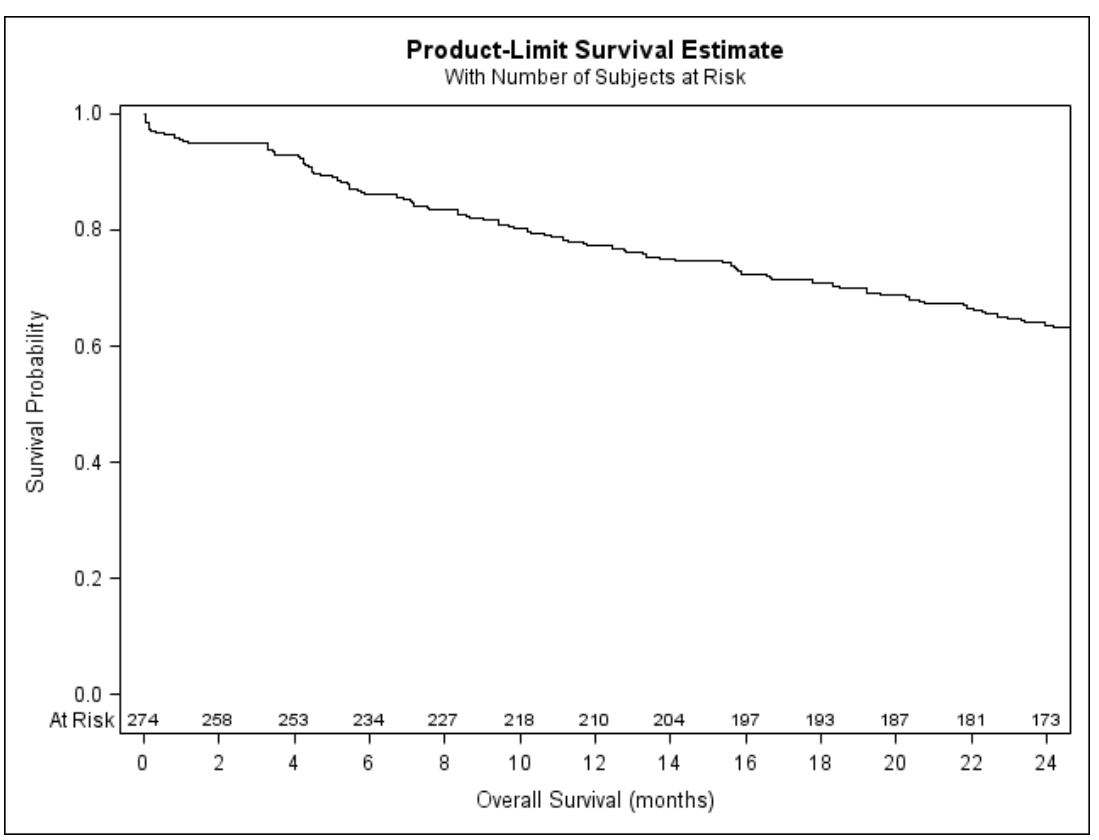

Supplementary Fig. 1 Chart shows two-year survival curve of the study population, with mortality rates at one year and two years of $22.6 \%(n=62)$ and $36.5 \%(n=100)$, respectively. 


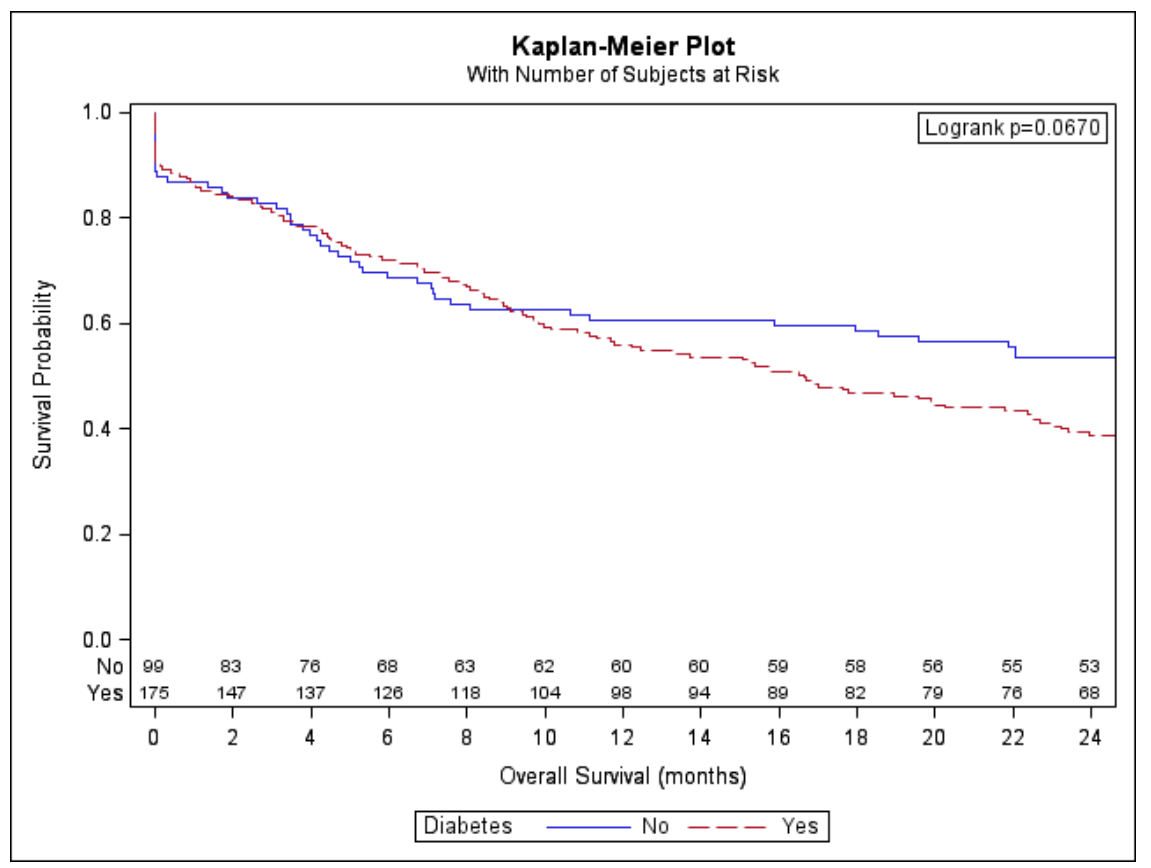

Supplementary Fig. 2 Chart shows two-year Kaplan-Meier curve for major adverse cardiovascular events (MACE) stratified by the presence of diabetes mellitus (DM). There was a trend towards lower two-year MACE-free survival in DM compared to non-DM patients, although this relationship was not statistically significant. (two-year MACE-free survival: $39 \%$ vs. 54\%, $p=0.0670$ ). 